\title{
Extent of Hyperostotic Bone Resection in Convexity Meningioma to Achieve Pathologically Free Margins
}

\author{
Hussein Fathalla, ${ }^{1}$ Mohamed Gaber Abdel Tawab, ${ }^{2}$ Ahmed El-Fiki \\ Division of Neurosurgery, Cairo University Hospitals, Cairo, Egypt \\ Division of Neurosurgery, ${ }^{2}$ Fayoum University, Fayoum, Egypt
}

Objective : Hyperostosis in meningiomas can be present in $4.5 \%$ to $44 \%$ of cases. Radical resection should include aggressive removal of invaded bone. It is not clear however to what extent bone removal should be carried to achieve pathologically free margins, especially that in many cases, there is a T2 hyperintense signal that extends beyond the hyperostotic bone. In this study we try to investigate the perimeter of tumour cells outside the visible nidus of hyperostotic bone and to what extent they are present outside this nidus. This would serve as an initial step for setting guidelines on dealing with hyperostosis in meningioma surgery.

Methods : This is a prospective case series that included 14 patients with convexity meningiomas and hyperostosis during the period from March 2017 to August 2018 in two university hospitals. Patients demographics, clinical, imaging characteristics, intraoperative and postoperative data were collected and analysed. In all cases, all visible abnormal bone was excised bearing in mind to also include the hyperintense diploe in magnetic resonance imaging (MRI) T2 weighted images after careful preoperative assessment. To examine bony tumour invasion, five marked bone biopsies were taken from the craniotomy flap for histopathological examinations. These include one from the centre of hyperostotic nidus and the other four from the corners at a 2-cm distance from the margin of the nidus.

Results : Our study included five males (35.7\%) and nine females (64.3\%) with a mean age of 43.75 years (33-55). Tumor site was parietal in seven cases (50\%), fronto-parietal in three cases (21.4\%), parieto-occipital in two cases (14.2\%), frontal region in one case and bicoronal (midline) in one case. Tumour pathology revealed a World Health Organization (WHO) grade I in seven cases (50\%), atypical meningioma (WHO II) in five cases (35.7\%) and anaplastic meningioma (WHO III) in two cases (14.2\%). In all grade I and II meningiomas, bone biopsies harvested from the nidus revealed infiltration with tumour cells while all other bone biopsies from the four corners ( $2 \mathrm{~cm}$ from nidus) were free. In cases of anaplastic meningiomas, all five biopsies were positive for tumour cells.

Conclusion : Removal of the gross epicentre of hyperostotic bone with the surrounding $2 \mathrm{~cm}$ is adequate to ensure radical excision and free bone margins in grade I and II meningiomas. Hyperintense signal change in MRI T2 weighted images, even beyond visible hypersototic areas, doesn't necessarily represent tumour invasion.

Key Words : Hyperostosis · Meningioma.

- Received : January 22, 2020 • Revised : February 23, 2020 •Accepted : March 30, 2020

- Address for reprints : Hussein Fathalla

Division of Neurosurgery, Cairo University Hospitals, Kasr el Aini street - Manial, Cairo, Egypt

Tel : +201201002554, Fax : +201201002554, E-mail : sehs.fathalla@gamil.com, ORCID : https://orcid.org/0000-0002-0736-7863

This is an Open Access article distributed under the terms of the Creative Commons Attribution Non-Commercial License (http://creativecommons.org/licenses/by-nc/4.0) which permits unrestricted non-commercial use, distribution, and reproduction in any medium, provided the original work is properly cited. 


\section{INTRODUCTION}

Meningiomas represent up to $30 \%$ of intracranial tumours ${ }^{6,8}$. Local recurrence is commonly linked with atypical and anaplastic subtypes (grade II and grade III), which represent up to $10 \%$ to $40 \%$ of all meningiomas ${ }^{11,13,15)}$. Radicality is considered the most important factor affecting the rate of local tumour recurrence and is directly correlated with longterm clinical outcome $e^{17)}$.

In the epicentre of some intracranial meningiomas, adjacent bone may show hyperostosis and can be found in $4.5 \%$ to $44 \%$ of cases $^{6}$. Hyperostosis maybe due to localized infiltration of bone by tumour cells ${ }^{3,5,15,16)}$ that is also aided by hypervascularity surrounding the meningioma. Many other mechanisms have been discussed in the literature ${ }^{4,5)}$. While The significance of hyperostosis as a prognostic factor is not yet clear in benign meningiomas (World Health Organization [WHO] grade I), it is commonly associated with poor outcome in atypical meningiomas (WHO grade II ${ }^{7}$. We suspect the reason behind this association is failure to achieve a Simpson grade I resection with many cases with hyperostosis. Missing its presence either radiologically or intra-operatively, hyperostosis can be the epicentre of meningioma recurrence ${ }^{16}$. Radicality in meningiomas with hyperostosis should therefore include aggressive removal of invaded bone to ensure a Simpson grade I resection.

The problem with this strategy however, is that it is unclear to what extent hyperostotic bone resection should be carried to provide pathologically free margins. Should the surgeon just resect the gross abnormal bone and stop when apparently normal cortical and cancellous bone is seen all around, or should the resection be wider just in case. To further complicate matters, most cases will have an abnormal T2 signal in the magnetic resonance imaging (MRI) that extends beyond the margins of the hyperostosis. In many centers, intraoperative frozen section of the bone could be examined to confirm negative bone margins but this is not always available, especially in emergencies. Because the current practice is very subjective in regards of extent of bone removal, guidelines should be set for this issue. In this study we try to investigate the perimeter of tumour cells outside the visible nidus of hyperostotic bone and to what extent they are present outside this nidus. This would hopefully guide us on how much bone removal should be taken to obtain a safety margin for these tumours and hence prevent recurrence.

\section{MATERIALS AND METHODS}

This is a prospective case series that included 14 patients with convexity meningiomas and hyperostosis during the period from March 2017 to August 2018 in Neurosurgery departments. After review and approval of the Ethical Committee Board of Cairo University Neurosurgery Department (IRB), all patients' demographics, clinical, imaging characteristics, intraoperative and postoperative data were collected and analysed. We always confirm the presence of hyperostosis both intraoperatively and preoperatively with computerized topography (CT) bone window and complementary MRI T2 weighted images.

\section{Operative protocol}

Our usual protocol in dealing with hyperostotic bone in convexity meningioma is to remove all areas of visibly abnormal bone, bearing in mind to also include the hyperintense diploe in MRI T2 weighted images after careful preoperative assesment and planning. This is somehow similar to how the invaded dura is delt with i.e., resect all thickened dura sur-

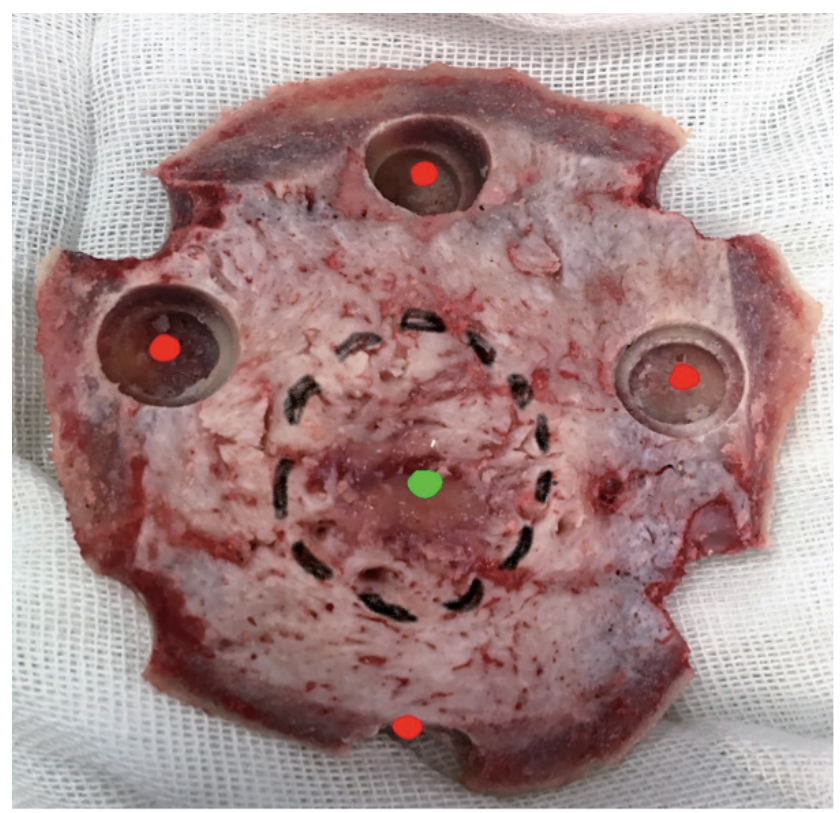

Fig. 1. Sites of bone biopsies : green point is the nidus epicentre (1st biopsy) and the margin of the nidus is outlined with a black dotted circle. The four red points are the corner biopsies and taken at $2 \mathrm{~cm}$ distance from the nidus margin. 
rounding the dura of origin to acquire Simpson grade I radical excision.

In all cases, after tumor resection, five marked bone biopsies were taken from the craniotomy flap for histopathological examinations including one from the centre of hyperostotic nidus and the other four biopsies from corners. These four corner biopsies were taken at a 2-cm distance from the margin of the hyperostotic nidus (Figs. 1 and 2). We used electric or manual twist drill to obtain all biopsies, which were kept in a separate marked cup. The skull defect was repaired using polymethyl methacrylate (PMMA) after insuring duroplasty with the pericraium covering the bone flap.

\section{RESULTS}

Our study included five male patients (35.7\%) and nine females $(64.3 \%)$ with age ranging from 33 to 55 years with mean 43.75 years. Weakness was the presenting symptom in four cases $(28.5 \%)$, convulsions occurred in five patients $(35.7 \%)$ while headache was the primary complain in nine cases (64.3\%). Most common site was the parietal region in seven
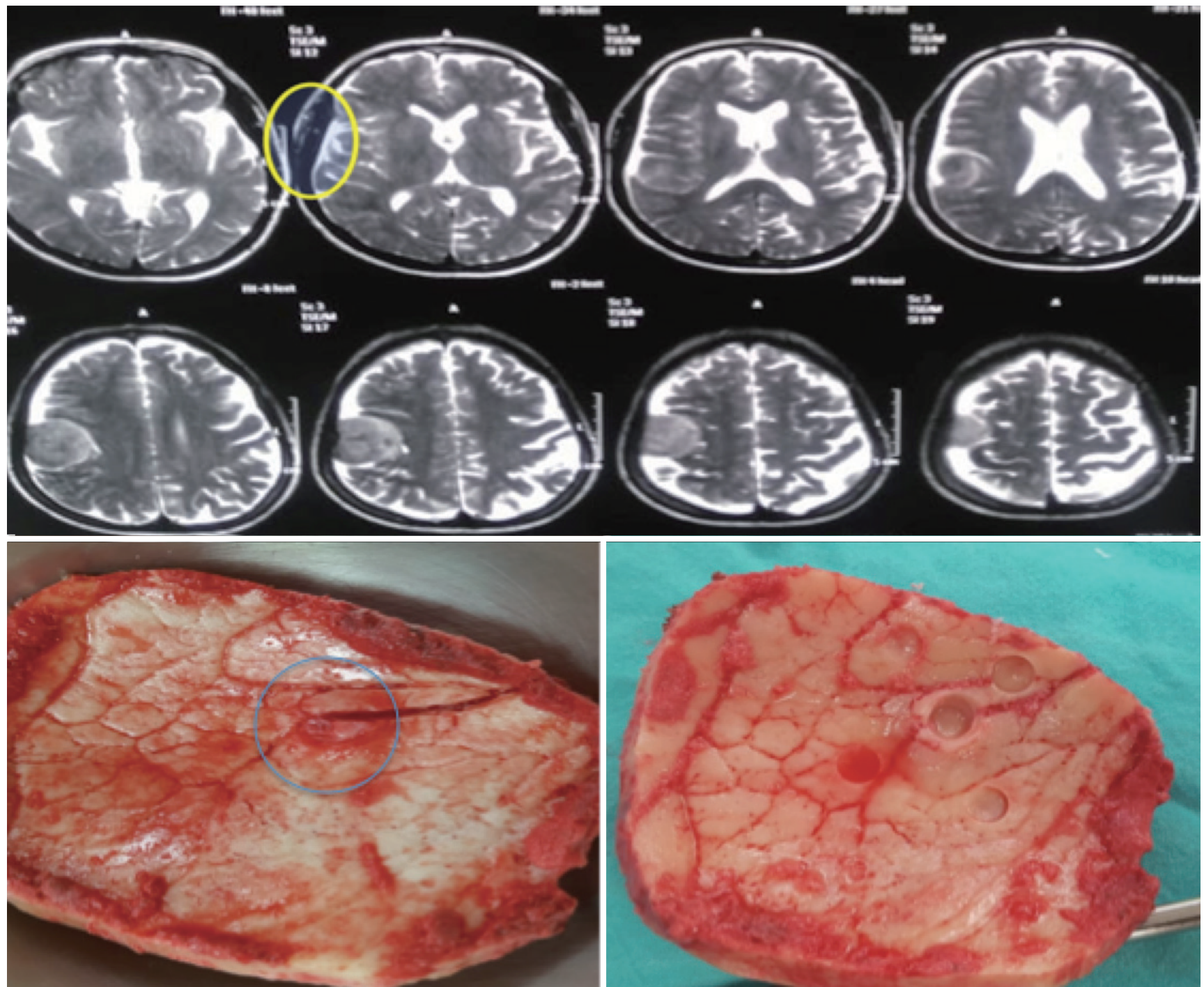

Fig. 2. Upper : magnetic resonance imaging (MRI) T2 axial images of one of the patients showing the hyperintense bone signal beyond the tumor (yellow circle). Lower left : picture of the craniotomy flap including the abnormal bone in MRI and showing a hyperostotic nidus (blue circle). Lower right : bone biopsies taken from the visible nidus and at $2 \mathrm{~cm}$ margins. As with all grade I and II meningiomas in this series, the center biopsy (from the nidus) yielded positive results while all corner biopsies ( $2 \mathrm{~cm}$ away) returned negative. 
cases $(50 \%)$ followed by frontoparietal region in three cases (21.4\%), parieto-occipital in two cases (14.2\%), frontal region in one case and bicoronal (midline) in one case. Radical excision was achieved in $100 \%$ of cases with Simpson grade I plus removal of the whole bone flap including the hyperostotic part. Tumour pathology revealed meningioma (WHO I) in seven cases (50\%), atypical meningioma (WHO II) in five cases (35.7\%) and anaplastic meningioma (WHO III) in two cases (14.2\%). All results are summarised in Table 1.

In all cases, preoperative MRI T2 weighted imaging revealed an abnormal hyperintense signal extending beyond the margin of hyperostotic bone (Fig. 2). In all grade I and II meningiomas, bone biopsies that were harvested from the nidus revealed infiltration with tumour cell while all other bone biopsies from the four corners $(2 \mathrm{~cm}$ from nidus) were free of tumour cells. In the two cases of malignant grade III meningiomas, all five biopsies were positive for tumor cells.

All patients had a Smooth postoperative recovery with improvement of symptoms in relation to pre-operative symptoms. Only three cases developed postoperative surgical site seroma, which resolved spontaneously with no secondary infection.

\section{DISCUSSION}

Meningiomas are the most common benign intracranial tumour $^{10,14)}$. Hyperostosis is most commonly present in skull base and convexity meningiomas and may be found in up to $44 \%$ of cases ${ }^{4,9)}$. Hyperostosis may occur due to irritation by the adjacent tumour up to bone invasion by meningiomatous cell with secondary hypervascularity in diploe of surrounding area of the skull. CT with bone widow is an essential pre-operative investigation to clue tumour invasion site.

MRI T2 images usually show hyperintense signal that sometimes extend beyond the hyperostotic nidus in imaging. Since radical excision is critical to minimize recurrence in meningiomas, We aimed to examine whether these regions of hyperintense signal surrounding the hyperostotic nidus are infiltrated with tumour cell or not. Interestingly, our results showed that in grade I and II meningiomas, there are no tumor cells beyond the $2 \mathrm{~cm}$ margin of the hyperostototic nidus. MRI T2 hyperintensity surrounding the hyperostotic bone is thus not an indication of bone tumor invasion.

Many authors assume that one centimetre circumferentially is enough as a safety margin, but this was not dependant on pathological confirmation. Marbacher et al. ${ }^{12)}$ prefer only to remove the grossly elevated part of hyperostosis with expected

Table 1. Demographic data, clinical picture, pathology and outcome of study populations

\begin{tabular}{|c|c|c|c|c|c|c|c|c|}
\hline \multirow{2}{*}{ Case No. } & \multirow{2}{*}{ Age/sex } & \multirow{2}{*}{ Presentation } & \multirow{2}{*}{ Site } & \multirow{2}{*}{$\begin{array}{l}\text { Simpson's } \\
\text { grade }\end{array}$} & \multirow{2}{*}{$\begin{array}{l}\text { WHO } \\
\text { grade }\end{array}$} & \multicolumn{2}{|c|}{ Bone pathology } & \multirow{2}{*}{ Complication } \\
\hline & & & & & & Corner & Centre & \\
\hline 1 & $45 / \mathrm{M}$ & Headache & Fronto-parietal & 0 & $\|$ & $N$ & $P$ & No \\
\hline 2 & $43 / F$ & Headache, fits & Parietal & 0 & $\|$ & N & $P$ & No \\
\hline 3 & $42 \mathrm{M}$ & Weakness & Parietal & 0 & । & $\mathrm{N}$ & $P$ & No \\
\hline 4 & $39 / F$ & Fits & Frontal & 0 & । & $\mathrm{N}$ & $P$ & Subcutaneous collection \\
\hline 5 & $50 / \mathrm{M}$ & Weakness & Bicoronal/midline & 0 & III & $P$ & $P$ & No \\
\hline 6 & $33 / F$ & Headache, fits & Parieto-occipital & 0 & I & $\mathrm{N}$ & P & No \\
\hline 7 & $42 / F$ & Headache, Fits & Parieto-occipital & 0 & I & $\mathrm{N}$ & $P$ & No \\
\hline 8 & $47 / F$ & Weakness & Parietal & 0 & $\|$ & N & P & No \\
\hline 9 & $52 / \mathrm{M}$ & Headache & Parietal & 0 & $\|$ & $\mathrm{N}$ & P & Subcutaneous collection \\
\hline 10 & $35 / F$ & Headache & Fronto-parietal & 0 & I & $\mathrm{N}$ & $P$ & No \\
\hline 11 & $42 / F$ & Weakness & Parietal & 0 & $\|$ & $\mathrm{N}$ & P & No \\
\hline 12 & $55 / \mathrm{M}$ & Headache, fits & Fronto-parietal & 0 & । & $\mathrm{N}$ & $P$ & Subcutaneous collection \\
\hline 13 & $43 / F$ & Headache & Parietal & 0 & 1 & $\mathrm{~N}$ & $P$ & NO \\
\hline 14 & $41 / F$ & Fits & Parietal & 0 & III & $P$ & $P$ & NO \\
\hline
\end{tabular}

WHO : World Health Organization, $M$ : male, $N$ : negative, $P$ : positive, $F$ : female 
to harbour meningiomatous cell and extend bone removal $1 \mathrm{~cm}$ around for safety. Our results confirm these findings pathologically. In our series (Fig. 2), the craniotomy always included the bone that showed the hyperintense T2 signal however, all bone biopsies from the craniotomy flap $2 \mathrm{~cm}$ away from the visible nidus showed no evidence of tumour cells This should have implications on how to interpret these MRI T2 signals in addition to establishing a future protocol for managing hypersostotic bone in meningioma surgery.

One should keep in mind that these results don't apply to grade III meningiomas. Our results showed that in all malignant meningiomas (grade III) tumor invasion was present beyond the one centimetre margin, evidenced by positive corner biopsies taken $2 \mathrm{~cm}$ from the visible nidus. Because these high-grade tumors are essentially malignant mesenchymal tumors resembling sarcomas and not true meningiomas, this was somehow expected ${ }^{18)}$. Whenever history and radiological findings suggest a grade III meningioma, aggressive excision of bone beyond the nidus and including all abnormal areas on preoperative MRI is warranted ${ }^{19)}$.

Many options are available to deal with hyperostotic bone starting from monopolar cautery of the nidus with tumour invasion to removal of the whole hyperostotic bone flap and cranioplasty $^{1,10)}$. Our standard protocol was to remove the whole bone flap and do PMMA cranioplasty instead. After these results, our protocol has switched to only removal of the hyperostotic nidus with a $2 \mathrm{~cm}$ safety margin from the bone flap then replacing it again ${ }^{2}$. This avoids a huge skull defect and the problems associated with cranioplasty. If the defect in the bone flap is in visible areas, one can always fill this defect with a small piece of mesh or PMMA. All cases showed improvements of preoperative symptoms, only three cases developed subcutaneous collection, which was resolved spontaneously over 3 weeks. This might suggest an only mild serous reaction to PMMA material. No cerebrospinal fluid leak, pneumocephalus or any other complications occured ${ }^{22}$.

This study has some limitations. In addition to the small sample size, bone sampling error can't be ruled out especially that the corner biopsies may miss small areas in between them. The possibility to contain tumour cells however is very low as we harvested these biopsies from sites with the same gross picture regarding colour, thickness and contour. Future studies should include larger number and longer follow up for cases where hyperostotic bone was removed with mentioned technique and monitor recurrence rates.

\section{CONCLUSION}

Removal of the gross epicentre of hyperostotic bone with the surrounding $2 \mathrm{~cm}$ is adequate to ensure radical excision including pathology free bone margins. Hyperintense skull diploe signal change in MRI T2 weighted images, even beyond the hypersototic areas, doesn't necessarily represent tumour invasion. Larger number studies with longer follow up are important for confirmation.

\section{CONFLICTS OF INTEREST}

No potential conflict of interest relevant to this article was reported.

\section{INFORMED CONSENT}

Informed consent was obtained from all individual participants included in this study.

\section{AUTHOR CONTRIBUTIONS}

\author{
Conceptualization : HF \\ Data curation : HF, AEF \\ Formal analysis : HF, MGAT \\ Methodology : AEF \\ Project administration : MGAT \\ Visualization : HF, AEF, MGAT \\ Writing - original draft : HF, AEF, MGAT \\ Writing - review \& editing: HF
}

\section{ORCID}

Hussein Fathalla https://orcid.org/0000-0002-0736-7863

Mohamed Gaber Abdel Tawab https://orcid.org/0000-0002-7060-6898

Ahmed El-Fiki https://orcid.org/0000-0001-7822-3448 


\section{References}

1. Alzhrani $G$, Couldwell $W$ : Bony hyperostosis recurrence after complete resection of sphenoorbital meningioma. Cureus 9 : e1540, 2017

2. Banu MA, Szentirmai O, Mascarenhas L, Salek AA, Anand VK, Schwartz $\mathrm{TH}$ : Pneumocephalus patterns following endonasal endoscopic skull base surgery as predictors of postoperative CSF leaks. J Neurosurg $121: 961-975,2014$

3. Bonnal J, Thibaut A, Brotchi J, Born J : Invading meningiomas of the sphenoid ridge. J Neurosurg 53 : 587-599, 1980

4. Di Cristofori A, Del Bene M, Locatelli M, Boggio F, Ercoli G, Ferrero S, et al. : Meningioma and bone hyperostosis: expression of bone stimulating factors and review of the literature. World Neurosurg 115 : e774e781, 2018

5. Derome PJ, Guiot $\mathrm{G}$ : Bone problems in meningiomas invading the base of the skull. Clin Neurosurg 25 : 435-451, 1978

6. Dziuk TW, Woo S, Butler EB, Thornby J, Grossman R, Dennis WS, et al. : Malignant meningioma: an indication for initial aggressive surgery and adjuvant radiotherapy. J Neurooncol 37 : 177-188, 1998

7. Gabeau-Lacet D, Mohapatra G, Betensky R, Barker F, Loeffler J, Louis D : Bone involvement predicts poor outcome in atypical meningioma. Int J Radiat Oncol Biol Phys 72 : S207, 2008

8. Goyal LK, Suh JH, Mohan DS, Prayson RA, Lee J, Barnett GH : Local control and overall survival in atypical meningioma: a retrospective study. Int J Radiat Oncol Biol Phys 46 : 57-61, 2000

9. Goyal N, Kakkar A, Sarkar C, Agrawal D : Does bony hyperostosis in intracranial meningioma signify tumor invasion? A radio-pathologic study. Neurol India 60 : 50-54, 2012

10. Lau BL, Che Othman MI, Fathil MFMD, Liew DNS, Lim SS, Bujang MA, et al. : Does putting back hyperostotic bone flap in meningioma surgery cause tumor recurrence? An observational prospective study. World Neurosurg 127 : e497-e502, 2019

11. Louis DN, Perry A, Reifenberger G, von Deimling A, Figarella-Branger D, Cavenee WK, et al. : The 2016 World Health Organization classification of tumors of the central nervous system: a summary. Acta Neuropathol $131: 803-820,2016$

12. Marbacher S, Coluccia D, Fathi AR, Andereggen L, Beck J, Fandino J : Intraoperative patient-specific reconstruction of partial bone flap defects after convexity meningioma resection. World Neurosurg 79 : 124130, 2013

13. Milker-Zabel S, Zabel A, Schulz-Ertner D, Schlegel W, Wannenmacher M, Debus I : Fractionated stereotactic radiotherapy in patients with benign or atypical intracranial meningioma: long-term experience and prognostic factors. Int J Radiat Oncol Biol Phys 61 : 809-816, 2005

14. Nasseri K, Mills JR : Epidemiology of primary brain tumors in the Middle Eastern population in California, USA 2001-2005. Cancer Detect Prev 32 : 363-371, 2009

15. Palma L, Celli P, Franco C, Cervoni L, Cantore G : Long-term prognosis for atypical and malignant meningiomas: a study of 71 surgical cases. Neurosurg Focus 2 : E3, 1997

16. Pieper DR, Al-Mefty O, Hanada Y, Buechner D : Hyperostosis associated with meningioma of the cranial base: secondary changes or tumor invasion. Neurosurgery 44 : 742-747, 1999

17. Simpson $D$ : The recurrence of intracranial meningiomas after surgical treatment. J Neurol Neurosurg Psychiatry 20 : 22-39, 1957

18. Willis J, Smith C, Ironside JW, Erridge S, Whittle IR, Everington D : The accuracy of meningioma grading: a 10-year retrospective audit. Neuropathol Appl Neurobiol 31 : 141-149, 2005

19. Zwirner K, Paulsen F, Schittenhelm J, Gepfner-Tuma I, Tabatabai G, Behling $F$, et al. : Integrative assessment of brain and bone invasion in meningioma patients. Radiat Oncol 14 : 132, 2019 